\title{
Not taking yourself too seriously in Australian English: Semantic explications, cultural scripts, corpus evidence
}

CLIFF GODDARD

\section{Abstract}

In the mainstream speech culture of Australia (as in the UK, though perhaps more so in Australia), taking yourself too seriously is culturally proscribed. This study applies the techniques of Natural Semantic Metalanguage (NSM) semantics and ethnopragmatics (Goddard 2006b, 2008; Wierzbicka 1996, 2003, 2006a) to this aspect of Australian English speech culture. It first develops a semantic explication for the language-specific expression taking yourself too seriously, thus helping to give access to an "insider perspective" on the practice. Next, it seeks to identify some of the broader communicative norms and social attitudes that are involved, using the method of cultural scripts (Goddard and Wierzbicka 2004). Finally, it investigates the extent to which predictions generated from the analysis can be supported or disconfirmed by contrastive analysis of Australian English corpora as against other English corpora, and by the use of the Google search engine to explore different subdomains of the World Wide Web.

\section{Introduction}

This study applies the analytical methods of NSM semantics and ethnopragmatics (Goddard 2006b, 2008; Peeters 2006; Wierzbicka 1996, 2003, 2006a) to an aspect of the mainstream Australian English speech culture; namely, the cultural injunction against taking yourself too seriously, and explores the potential for corpus techniques to contribute supporting linguistic evidence. By ethnopragmatics, I refer to the quest to identify and articulate explanatory "insider perspectives" on speech practices, by identifying and articulating the semantic content of culture-specific concepts and attitudes. Such a venture demands a rigorous semantic methodology, which can facilitate the maximum clarity and resolution of meaning, and at the same time avoid the dangers of terminological ethnocentrism. The 
NSM methodology adopted in this study satisfies these requirements. It uses simple cross-translatable words as its descriptive vocabulary, both for semantic explications (to articulate the semantic content of words and other linguistic expressions) and for formulating cultural scripts (to capture shared assumptions and norms of communication).

In the course of the investigation, various hypotheses emerge about the relative frequencies of certain key expressions in Australian English, as opposed to American English and British English. In the final sections of the study I address the question of how these hypotheses can be tested using corpus techniques, and how corpus explorations may bring to light additional evidence for or against hypotheses arising out of ethnopragmatic analysis. A methodological issue of some interest concerns the relative merits and dangers of using Cobuild Word Bank of English, Ozcorp, and other standard corpora, as opposed to using the World Wide Web and the Google search engine. The final section of the paper contains discussion of difficulties and the limitations of the study, and some concluding remarks.

\section{Not taking yourself too seriously: A key Australian cultural value?}

Commentators on Australia frequently remark on the importance and widespread provenance of joking in Australian society, and, in particular, on the importance Australians place on being able to laugh at themselves. For example, in her popular guide Culture Shock! Australia, Ilsa Sharp (2001: 15) states that: "[L]ike their British ancestors, they are blessed with a limitless capacity for self-mockery, always a healthy trait". Cultural historian John Thornhill sees a link between Australian egalitarianism and its characteristic "leveling humor": "Australia's egalitarian ethos expresses itself in a humour which deflates the pretensions of those who take themselves or their causes too seriously" (Thornhill 1992: 133; italics added). Of course, it is important to remember that an abstract term like "egalitarian" can apply to a range of cultural situations; or, to put it another way, that egalitarianism can come in different cultural flavors. Australian egalitarianism tends to cut across public recognition of individual achievements. Graeme Davidson, professor of Australian history at Monash University, thinks that this helps to explain Australia's anti-heroic streak: "Forty years ago, we used to rejoice in the fact that we had few heroes and the ones we did were people like Ned Kelly or 'types', such as the Anzac .... It's a big sin in Australia to take yourself too seriously or place yourself on a pedestal" (quoted in Kissane 2002; italics added). There is also the well-known Australian "tall poppy syndrome" (Peeters 
2004a, 2004b) - roughly, the propensity to "cut down" individuals who appear to enjoy a sense of achievement which would set them apart from other people.

Arguably, not taking ourselves too seriously is part of the national selfimage, as indicated in the following quotation from the ICE-Australia corpus of newspaper editorials: "We are an easy-going nation with a long, happy tradition of social egalitarianism, of not taking ourselves, or anything else, too seriously" (italics added). The former Premier of New South Wales, Bob Carr, articulated similar attitudes in his 2003 essay What Australia Means to Me. Expanding on an earlier account of what he had described as "a funny, friendly, benign country" (5), he says: "Perhaps I'd add now: an unpretentious country. [...] I like the way we look with amusement on much that others take seriously: pomposity in high places, empty ceremony, excessive flag-waving, elaborate class distinction" (Carr 2003: 19-20; italics added). Reflecting on the "wide and subtly ramified levity" of Australia's vernacular culture, the Australian poet Les Murray (1999: 26-27) identifies what he calls the "clown-icon" as a national-level manifestation of the Australian imperative not to take yourself too seriously. Murray is referring to national icons such as tomato sauce, the meat pie, blowflies, lawn mowers, zinc cream, Hills hoist clothes-lines, and so on, which puzzled many overseas viewers of the Opening Ceremony of the Sydney Olympic Games in 2000 (especially in the "Tin Symphony" segment, which was widely described as "quintessentially Australian", cf. [www.specialevents.com.au/archiveprev/ sydney2000/opening.html]). ${ }^{1}$

Some of these cultural themes are substantially inherited from British English (cf. Malouf 2004). In her book Watching the English, social anthropologist Kate Fox (2004) elevates the "Importance of Not Being Earnest" to the status of a British English cultural rule which, in her opinion, cannot be emphasized enough: "Serious matters can be spoken of seriously, but one must never take oneself too seriously" (Fox 2004: 62; italics in original).

Because it will be relevant when we come to look at corpus evidence, I would like to note at this point an important Australian and British English speech practice ${ }^{2}$ that supports and reinforces the proscription on taking yourself too seriously - namely, the "anti-pretentious" speech practice of taking the piss/mickey (out of someone) (Olivieri 2003; Davis 2007; Haugh 2008). Many dictionaries make it seem synonymous with "send up, make fun of, tease", but The Australian Oxford Dictionary (1999) comes closer to the true meaning by defining it as "ridicule; humble, puncture the pretensions of." In an insightful semantic treatment of teasing and related speech-acts, Olivieri (2003) remarks as follows: "It is 
like a warning that people can disapprove of the way that the target of the speech act supposedly acts or thinks - the purpose of taking the piss out of someone is to make someone aware of the fact that someone thinks about some aspect of himself, or something he does, a little too seriously" (Olivieri 2003: 70; second italics added).

But what exactly does it mean to take something/someone seriously or to take yourself too seriously? I turn now to a detailed semanticconceptual analysis. As we will see, the meanings of these expressions are by no means simple, and, in case it needs saying, many languages of the world do not have any precise semantic equivalents. Semanticconceptual analysis using the NSM methodology can disclose the full semantic content of the concepts behind these words, and, at the same time, open up an "insider perspective" on them.

\section{The NSM method of semantic analysis}

The general assumptions of the NSM approach will likely be familiar to many readers, following the recent debates between Wierzbicka (2007a, 2007b) and Jackendoff (2007) in this journal. Nonetheless, it may be helpful to review the main assumptions and procedures (Wierzbicka 1996; Goddard and Wierzbicka 1994, 2002; Peeters 2006; Goddard 2008). The key idea is a very simple one: in order to explain anything successfully, the terms in which we do the explaining must be simpler and more intelligible than the ones we are explaining. This means that the most effective technique for explaining the meaning of a word in a given context is reductive paraphrase, i.e. saying the same thing in simpler words. By insisting on strictly reductive paraphrase the NSM approach aims to escape from the circularity, abstractness and obscurity that mar most dictionary definitions, and most scholarly practice in semantics.

Plainly, the reductive paraphrase procedure implies the existence of a terminal set of simple indefinable meanings. NSM researchers claim to have discovered this set of meanings (semantic primes) via a long and incremental program of experimentation with semantic analysis, extending from Wierzbicka (1972) through to Goddard (2008), and continuing. They also advance the claim, backed by studies of typologically diverse languages, that semantic primes have concrete lexical exponents (words, phrasemes, or bound morphemes) in all or most languages. These are of course far-reaching claims, and it would be impossible to discuss them fully or attempt to justify them in this paper. The point here is to explain the background to the vocabulary of semantic representation employed in the present study. 
Table 1. Semantic primes (English exponents), grouped into related categories

\begin{tabular}{|c|c|}
\hline I, YOU, SOMEONE, SOMETHING/THING, PEOPLE, BODY & substantives \\
\hline KIND, PART & relational substantives \\
\hline THIS, THE SAME, OTHER/ELSE & determiners \\
\hline ONE, TWO, SOME, ALL, MUCH/MANY & quantifiers \\
\hline GOOD, BAD & evaluators \\
\hline BIG, SMALL & descriptors \\
\hline KNOW, THINK, WANT, FEEL, SEE, HEAR & mental predicates \\
\hline SAY, WORDS, TRUE & speech \\
\hline DO, HAPPEN, MOVE, TOUCH & actions, events, movement, contact \\
\hline $\begin{array}{l}\text { BE (SOMEWHERE), THERE IS, HAVE, BE (SOMEONE/ } \\
\text { SOMETHING) }\end{array}$ & $\begin{array}{l}\text { location, existence, possession, } \\
\text { specification }\end{array}$ \\
\hline LIVE, DIE & life and death \\
\hline $\begin{array}{l}\text { WHEN/TIME, NOW, BEFORE, AFTER, A LONG TIME, } \\
\text { A SHORT TIME, FOR SOME TIME, MOMENT }\end{array}$ & time \\
\hline $\begin{array}{l}\text { WHERE/PLACE, HERE, ABOVE, BELOW, FAR, NEAR, } \\
\text { SIDE, INSIDE }\end{array}$ & space \\
\hline NOT, MAYBE, CAN, BECAUSE, IF & logical concepts \\
\hline VERY, MORE & intensifier, augmenter \\
\hline LIKE/WAY & similarity \\
\hline
\end{tabular}

Notes: Primes exist as the meanings of lexical units (not at the level of lexemes). Exponents of primes may be words, bound morphemes, or phrasemes. They can be formally complex. They can have combinatorial variants (allolexes). Each prime has wellspecified syntactic (combinatorial) properties.

From a theoretical point of view, the NSM metalanguage can be thought of as a highly disciplined and standardized subset of natural language: a small subset of word-meanings (63 in number), together with a subset of their associated grammatical properties. From a practical point of view, one can simply think of semantic primes, such as PEOPLE, SOMEONE, DO, SAY, WANT, KNOW, THINK, GOOD, BAD, BECAUSE, as a controlled vocabulary of plain simple words used for the purpose of semantic explication. A full table of semantic primes is given in Table $1 .^{3}$

NSM semantic explications are reductive paraphrases composed within this highly constrained vocabulary. As far as I am aware, NSM is the only semantic approach to employ paraphrase in a strict sense. Many systems seek to describe meaning in decompositional terms, but decompositional or not, there is an enormous difference between paraphrase and description. Paraphrase attempts to capture an insider perspective, with its sometimes naïve first-person quality, rather than the sophisticated outsider perspective of an expert linguist, logician, etc. Equally, paraphrase requires formulation in terms which are accessible and intelligible to the speakers concerned. The intelligibility of NSM explications to native speakers and the close relationship between the metalanguage and the 
language being described makes it easy to generate and test hypotheses: by direct or indirect substitution into natural contexts of use, and by direct accessibility to native speaker intuition.

Notwithstanding the fact that in the NSM approach, all meaning description is ultimately grounded in semantic primes, it is acknowledged that words in some areas of the lexicon resist resolution directly and immediately into semantic primes. Especially for words in the concrete lexicon, NSM explications often consist of a combination of semantic primes along with other relatively simple, but non-primitive, words - termed "semantic molecules" (Goddard 2007a). For example, explications for physical activity verbs such as walk and drink include body-part meanings such as "feet" and "mouth" as semantic molecules. When they are used in semantic explications, semantic molecules are marked as such with the notation [M]. Semantic molecules can of course themselves be explicated, in a non-circular fashion, into semantic primes. Of particular relevance to the analysis presented in this paper is the assumption that the word "laugh" is a semantic molecule, appearing in concepts such as "joking", "humor", "light-heartedness", and the like (Wierzbicka in press).

\section{Not taking yourself too seriously — what exactly does it mean?}

The word serious has several distinct meanings, each of which is matched by a corresponding meaning of the adverb seriously. Only a partial coverage will be presented here, but even this requires us to consider five semantic explications, as follows: [A] being serious, saying something seriously, [B1] being serious about something, [B2] taking something seriously, [C1] taking someone seriously, [C2] taking yourself too seriously.

On my analysis, the semantically simplest use of the word serious is when it is used by a person saying something, as in the following examples. These and subsequent examples are all naturally occurring, drawn from my own observations or from standard corpora of Australian English or British English.

(1) Alex, I'm serious. I'll be out of a job if I'm late again.

(2) I'm serious about that by the way, I really do meditate.

(3) What would you qualify as sufficient research? I'm serious here, not just taking the piss out of you.

In examples like these, the speaker who says I'm serious is essentially just saying "I'm not joking when I say this." The meaning can be captured as in explication [A]. It characterizes the speaker's way of speaking by means of a kind of "counter-analogy" to how "people can say something 
when they say it because they want someone to laugh [M]." Because being serious is in an implicit contrast with joking, it incorporates reference to the (non)possibility of laughing.
[A] (-Are you serious ${ }_{A}$ ?) Yes, I'm serious $A$ :
a. when I said it,
b. I said it not like people say something when they say it because they want someone to laugh [M]

A second, and more complex, meaning is found in expressions which describe a person as being serious about something - about a topic, activity, proposal or the like, which could have implications for how the subject thinks and acts. For example:

(4) People were always telling me I shouldn't be so serious about my thesis.

(5) If you're serious about buying a property ...

(6) He is so serious about it that he has quit his job.

This meaning is explicated in [B1] below. Here serious describes someone's attitude, i.e., how this person thinks about a certain topic, activity, etc. The nature of this attitude is spelt out in components (a)-(c). These capture the intuition that someone who is serious about something frequently thinks about it, regards it as something special, and feels obliged to devote considerable effort to it. The link with the simpler ("nonjoking") meaning $\operatorname{serious}_{A}$ is captured in component (d).

[B1] He's serious ${ }_{B}$ about it (dealing with this issue, improving his golf, his research, etc.):

a. at many times he thinks about it like this:

b. "this is something not like other things

c. I can't not do many things because of this"

d. when he thinks like this, he doesn't think like people think about something when they want to laugh $[\mathrm{M}]$ at the same time

Pretty well the same meaning is found in the expression to take something seriously, as illustrated in the examples below. Most take-constructions have counterparts (agnate constructions) with $\operatorname{serious}_{B}$ as a predicative adjective. For example, corresponding to example (7), we have: She is serious about her studies.

(7) She takes her studies seriously.

(8) "If they had taken it seriously and done something, Hayes might be alive today", said Mr Faris, a former chairman of the National Crime Authority. 
(9) ALC Chairman Bob Charley said the equine tragedy was being taken extremely seriously by his organization, and was under close scrutiny by government departments.

Explication [B2] shows how the meaning $\operatorname{serious}(l y)_{B}$ fits into the phrasal construction with take. Note that there is one additional component (component (d) "she wants to think about it like this"), connected with the more "active", intentional feel conveyed by the verb take.

[B2] She takes her studies seriously:

a. at many times she thinks about it [her studies] like this:

b. "this is something not like other things

c. I can't not do many things because of this"

d. she wants to think about it like this

e. when she thinks like this, she doesn't think like people think about something when they want to laugh [M] at the same time

Next we move to expressions in which the topic is not an activity or topic, but a person, i.e., expressions of the form taking someone seriously. In these expressions, the meaning of seriously is somewhat different, but there are significant parallels. First let us look through some examples. As one can see, they tend to occur in negative polarity sentences.

(10) I have not been able to take Glenda Jackson seriously since she faked that dramatic orgasm with Oliver Reed in the film Women in Love.

(11) Trouble with this place is that no-one around here takes me seriously.

(12) Women, to be taken seriously, had to dress in a more robust, sensible manner, they stated --; an argument amply demonstrated by their usefulness in wartime.

Taking someone seriously implies regarding that person as somewhat special, i.e. not like other people, and as someone who is capable of doing something worthwhile. It also implies that one is not inclined to laugh when thinking about that person. Conversely, not taking someone seriously implies that one might have to suppress a giggle when thinking about them. I propose explication [C1] below.

[C1] I can't take Glenda Jackson seriously :

a. I can't think about Glenda Jackson like this:

b. "she is someone not like other people

c. she can do good things" 
d. when I think about Glenda Jackson, I think about her like people think about someone when they want to laugh [M] at the same time

The same schema can be used when the topic or target is represented by a reflexive pronoun, if the cognitive construal is phrased in the firstperson. For example, when we say about someone that "He takes himself too seriously," we are saying that he willingly entertains thoughts such as "I am someone not like other people, I can do good things", and that when he thinks like this, it is not in a light-hearted or joking frame of mind.

This brings us to the key expression which is the focus of this study, namely, not taking yourself too seriously. Consider these examples:

(13) Some golfers take themselves too seriously. But life's too short for that.

(14) A: What makes you laugh? B: People who have an ability to take the piss out of themselves and not take themselves too seriously. That's fun.

To complete the picture developed to this point, we need to articulate the effect of the modifier too. Without undertaking a full consideration of too across a range of contexts, I would like to suggest that in this context the semantic effect combines "intensification" with the speaker's negative evaluation. In [C2], the intensification aspect is captured by the addition of "very" to component (c), and the negative evaluation is captured in component (f).

[C2] She takes herself too seriously:

a. at many times she thinks like this:

b. "I am someone not like other people"

c. I can do very good things:

d. she wants to think like this

e. when she thinks like this, she thinks not like people think about something when they can want to laugh [M] at the same time

f. this is not good

Explication [C2] is framed in the affirmative, but the semantic content of the negative version, i.e., not taking yourself too seriously, is now clear. To say that someone doesn't take themselves too seriously is to deny that they have the kind of undesirable attitude depicted in [C2].

This has not been an exhaustive coverage of the polysemy of serious and seriously (for example, we have not touched expressions such as $a$ 
serious illness, a serious matter, etc.) but it is sufficient for our purpose, namely, to articulate the semantic content of not taking yourself too seriously in clear and cross-translatable terms.

\section{The methodology of cultural scripts}

As a linguistic expression, not taking yourself too seriously is attested in all the major "inner circle" dialects of English, including American English and British English, as well as Australian English. Nevertheless, I would like to argue that not taking yourself too seriously is more highly proscribed by mainstream communicative norms in Australia than it is in the USA, and perhaps even in the UK. In this section, I briefly outline the theory of cultural scripts, which is the pragmatic "sister theory" of NSM semantics. Following the Special Issue on Cultural Scripts of this journal (Goddard and Wierzbicka 2004; cf. Goddard 2007b), many readers will be familiar with the basic approach, but some background may still be useful. Perhaps it is easiest to introduce it by way of a contrast.

In the social science literature, cultural differences between Australia and the USA, for example, are typically characterized in terms of abstract sociological parameters; for example, "horizontal individualism" (Australia) vs. "vertical individualism" (USA) (Hofstede 1997; Singelis and Triandis et al. 1995). In linguistic pragmatics, a standard approach is the "politeness theory" developed by Brown and Levinson (1987 [1978]) and subsequent works. Though different from one another in many respects, what these approaches have in common is that they represent "outsider perspectives." It can hardly be otherwise, given that the descriptions are framed in technical or scholarly terms which would be unrecognizable to native speakers.

Cultural scripts, by contrast, are stated in ordinary non-technical language, using the same metalanguage of semantic primes that is used in lexical semantic analysis (Wierzbicka 2003; 1994; Goddard and Wierzbicka 1997). This does mean that cultural scripts are the same in nature as semantic explications. Cultural scripts are not paraphrases of actual lexical items, but "representations of cultural norms which are widely held in a given society and are reflected in the language" (Wierzbicka 2007c: 56). "They constitute a certain naïve axiology, that is, a naïve set of assumptions about what it is good and bad to do or say, and even to think and feel. Any given speech community has such shared assumptions, and although not everyone necessarily agrees with them, everyone is familiar with them because they are reflected in the language." 
One of the key concerns of work in the cultural scripts framework has been to denaturalize the pragmatics of English (cf. Wierzbicka 2003, 2006a; Peeters 2000), so I will illustrate what cultural scripts look like with a proposed high-level script of mainstream Anglo culture. A wide range of sociological, historical and culture-analytical literature indicates that something like "personal autonomy" is one of the primary ideals of Anglo culture. Script [D] is intended to capture an important aspect of this ideal.

[D] Anglo cultural script favoring "personal autonomy"

a. people think like this:

b. when someone does something, it is good if this someone can think about it like this:

c. "I am doing this because I want to do it"

Wierzbicka (2003, 2006a, 2006b) has argued at length that this ideal is largely responsible for the strong preference among speakers of mainstream Anglo English to use interrogative directives (wh-imperatives) such as Will you ...?, Would you ...?, Can you ...?, Could you ...?, Would you mind ...? , rather than bare imperatives. Although the interrogative directives clearly convey the message "I want you to do this", they acknowledge the addressee's autonomy by embedding this potentially confronting message into a question-form, as if inviting the addressee to say whether or not he or she will comply.

Despite the possible connotations of the word "script", it is important to stress that cultural scripts are not binding on individuals. They are not proposed as rules of behavior, or as descriptions of behavior, but as normative rules of interpretation and evaluation. It is up to individuals in concrete situations whether to follow (or appear to follow) culturally endorsed principles, and if so, to what extent; or whether to defy, manipulate, or subvert them, play creatively with them, etc. Whether or not cultural scripts are being followed in behavioral terms, however, the claim is that they constitute a kind of shared interpretive background. It also has to be stressed that there are complex inter-relationships between and among the large number of scripts operative in any culture, including various forms of intertextuality, e.g. some scripts being more general than others, some taking priority over others, some competing with others. Clearly, many scripts must be tailored to particular types of interlocutors, settings, and discourse genres. Equally clearly, and more to the point for the present study, cultural scripts can vary across different speech communities (communities of discourse practice) speaking a single language. 


\section{Cultural scripts disfavoring taking yourself too seriously}

I would like to suggest that there are at least two cultural scripts in Australian English that converge on disfavoring taking yourself too seriously. One of them is humor-related, and it is presumably shared both with British English and with American English. The other is connected with the Australian style of egalitarianism. In both cases, my argument builds on proposals, advanced on the basis of other evidence, by Anna Wierzbicka.

To appreciate the first of the proposed scripts, we first have to appreciate the potential value - from an Anglo culture-internal point of viewof being able to take a humorous view of almost any situation. An important observation made by Kate Fox (2004), in her Watching the English, which in my view applies also to Australia and to the USA, is that in England humor is almost never out of place. In many countries, Fox says, humor in its various forms is greatly appreciated - at the right time and in the right place. But in England (and, I would add, in Australia and the USA), it can appear in almost any situation or setting, no matter how apparently serious.

Wierzbicka (in press) provides semantic and corpus evidence for the importance of humor in Anglo speech culture in general, by way of a dedicated study of the expression a sense of humor (good sense of humor, great sense of humor, etc.). ${ }^{4}$ She makes the important observation that having a sense of humor is quite different from concepts like being funny or being witty, which refer to a person's ability or skills in making other people laugh. A sense of humor is not about a person's amusing cleverness or amusing way of behaving at all. Rather it refers to a person's supposed ability to find and appreciate the "funny" side of concrete realworld situations. The English-specific semantics of a sense of humor indicates the existence of an unusual culture-specific concept, and the relatively high frequency of the expression suggests that the concept is an important one in mainstream English-speaking societies. There is also ample evidence from sociological studies and other sources that most people in the UK, USA and Australia regard having a good sense of humor as a laudable character trait.

I would propose the following cultural script.

[E] Anglo cultural script favoring being able to "see the funny side" of many situations

a. people think like this:

b. at many times when something happens in a place, people in this place can laugh $[\mathrm{M}]$ if they think about it for a short time

c. it is good if it is like this 
Clearly, a cultural script like this one would tend to inhibit people from taking themselves too seriously. There is an implicit tension between "very often" thinking self-important or self-enhancing thoughts which preclude laughing at the same time, and the notion that one should be ready to laugh at almost any time. ${ }^{5}$ Not surprisingly then, when people are advised not to take themselves too seriously on these grounds, there is often reference to the need to "lighten up" and enjoy life.

We turn now to the second cultural attitude which contributes to the proscription in Australia against taking yourself too seriously, and which, I would argue, strengthens this proscription in comparison with British English and with American English. This aspect has nothing to do with humor or laughter as such. Rather it concerns that part of the taking yourself seriously attitude which concerns thinking about oneself "I am not like other people, I can do good things". This aspect of the meaning of taking yourself seriously clashes with important Anglo-Australian cultural scripts that, roughly speaking, endorse the presentation of the self as "ordinary", and, conversely, proscribe the appearance of wanting to be special and better than other people (cf. Goddard 2006a).

Most commentators recognize that an "egalitarianism of manners," to use historian John Hirst's (1998: 208) phrase, has long been a part of Australian social life. It is important to note that the claim here concerns "the feel of Australian society ... not its social structure" (Hirst 2006: 301). The point is one about interactional style, about communicative norms.

Some people claim that Australian society is not egalitarian because there are wide differences of income, which may now be getting wider. This misses the point of Australian egalitarianism. It is the way Australians blot out differences when people meet face to face. They talk to each other as if they are equals and they will put down anyone claiming social superiority. (Hirst 2006: 301)

In his classic work The Lucky Country, Donald Horne (1986[1964]) offers a description which comes close to an insider's perspective: "Australians like people to be ordinary" (33). They have "a deep belief in the essential sameness and ordinariness of mankind" (20).

Wierzbicka (2002: 1194-1195) has proposed the cultural script in [G] (presented here in a slightly modified form) to capture the core idea. Since appearing to "be like other people" is socially desirable, it follows that appearing to think of oneself in very positive terms, and by implication as not like other people, will be socially disapproved. This distaste for positive self-evaluation and feelings of "specialness" can be stated as in script $[\mathrm{H}]$. 
[G] Cultural script for a characteristically Australian social attitude

a. people think like this:

b. it is good if people can think like this about someone:

c. "this someone is someone like me"

[H] Australian cultural script discouraging positive feelings of "specialness"

a. people think like this:

b. it is bad if someone thinks like this:

c. "I am someone very good

d. I am not like other people"

Wierzbicka $(1992,2002,2003)$ has argued at length that these scripts, and others related to them, have numerous linguistic correlates in Australian discourse practices; for example, in aversion for titles, and the "purposeful rejection of overt shows of respect" generally, and, conversely, in the Australian preference for first-name address and other indicators of familiarity, informality and equality. ${ }^{6}$

What I want to draw attention to here is that such scripts would also have consequences for taking oneself seriously. They characterize an ethos, a community of opinion, in which it would be disapproved to regularly entertain thoughts such as "I am someone not like other people, I can do good things" - thoughts which we have seen to be characteristic of the attitude labeled as taking yourself too seriously.

If this line of argument is correct, it predicts that although taking yourself too seriously is disapproved of in other Anglo English countries such as the UK and the USA, it ought to be more strongly disapproved in Australia. This would be consistent with the ethnographic and other cultural commentary evidence adduced in section 2 . I will now turn to the question of whether corpus techniques can provide evidence for or against this prediction. In so doing, I am following Stubbs (2001), Mair (2007) and others, in the assumption that the relative frequencies of characteristic expressions in a given speech community reflect the social and cultural concerns of that speech community.

\section{Corpus evidence for ethnopragmatics: standard corpora}

If the claims and hypotheses about characteristic Australian English speech practices are correct, these ought to give rise to different usage patterns, differences which ought to show up in corpora of Australian English as opposed to American English and British English. What then can the available corpora tell us? 
Unfortunately, we are hampered by lack of comparability between available corpora, and, in particular, the much smaller size of existing Australian corpora. For example, in June 2007, the Cobuild Word Bank of English contained about 42.1 million words of UK English, about 10 million of US English, and only about 5.3 million words of Australian English. The Australian material, furthermore, is predominantly from a single source (the Brisbane newspaper The Courier Mail), with all the attendant problems of genre and register that this implies. Two other publicly available corpora of Australian English are the ACE (Australian Corpus of English) and ICE-Aus (International Corpus of EnglishAustralia), but they are only about 1 million words each in size. The largest corpus of Australian English is Ozcorp, at 25 million words. It is an in-house resource of the Macquarie Dictionary and is not freely available to outside researchers. Thanks to the generosity of the Macquarie Dictionary's publisher Sue Butler, I have been able to make some limited use of Ozcorp, as reported below, but there is another difficulty: Ozcorp is heavily weighted towards written materials, especially novels.

Regardless of these limitations, are there any significant distributional differences between the key "serious(ly) expressions" across these corpora? I place particular importance on occurrences of expressions of the form "NEG TAKE yourself too seriously", i.e., negated expressions with the reflexive pronoun in the second-person, because this is the form in which generic advice is given. In the available corpora, however, even the Cobuild-UK at 42.1 million words, the frequency of this expression is either zero or minute. A search for the string "yourself too seriously" across the three Cobuild corpora returned the following figures: CobuildUK: 0, Cobuild-US: 1, Cobuild-Aust: 0 .

If we sample a less specific expression, some suggestive figures appear. For example, the frequency of the string "too seriously" does seem to vary significantly across the three corpora. Table 2 gives absolute numbers and (for ease of comparison) a figure of average occurrences per million.

These figures might provide support for the proposition that critical comments to the effect that something is being taken too seriously are more common in Australia than in the UK or USA. On account of the

Table 2. Frequency of the string "too seriously" in three corpora of English

\begin{tabular}{llll}
\hline & Cobuild-Aust & Cobuild-UK & Cobuild-US \\
\hline absolute no. & 15 & 61 & 11 \\
no. per million & 2.8 & 1.4 & 1.1 \\
\hline
\end{tabular}


differences in size and composition of the three corpora, however, I think one ought to be cautious in attributing significance to these figures. Above all, one has the sense that Cobuild-Aust is too small and too skewed in terms of genre and register to provide reliable figures. This impression is reinforced by the fact that figures for the string "too seriously" in the larger Ozcorp corpus are significantly lower than in Cobuild-Aust: only 30 times in 25 million words.

\section{Corpus evidence for ethnopragmatics: the web}

In response to problems of this nature, Mair (2007) has proposed applying corpus techniques to the World Wide Web. He sampled webpages in different subdomains of the English-language Web with the goal of seeing whether certain lexical/phraseological markers of different varieties of English would show up with different frequencies. The goal was to develop collocational and cultural profiles of different varieties of English, based on "culturally motivated lexical variability" (p. 442). After comparing the distributions of a set of "neutral" collocations (e.g., deep breath, heavy rain) with the distributions of a set of collocations whose status as regional markers of "Britishness" is well established (e.g. bog standard, KNOCK for six, I should like to), he concluded: "the results of this comparison generally justify cautious optimism about the value of the Web as corpus for the purpose at hand" (443). Of particular relevance to our concerns is Mair's observation that traditional corpora-even the 100 million word British National Corpus - are too small to enable systematic regional comparisons, even of well-established regional markers such as the British cricket-based idiom KNOCK for six.

While the Web provides a vastly larger repository of machine-readable texts, the use of "webidence" is hampered by numerous difficulties, chiefly, the constant change in the size and composition of the Web itself, and the peculiarities of commercial search engines like Google and Yahoo (Fletcher 2007; Schmied 2006). As a way of getting around the peculiarities of search engines, some researchers advocate compiling their own dedicated corpora from the Web ("Web for Corpus" or WfC), while others advocate cautious use of search engines ("Web as Corpus" or $\mathrm{WaC}$ ), while trying to safeguard against their idiosyncrasies. These include the presence of multiple duplicate pages and variable indexing and ranking practices, such as use of link popularity, term salience, and geographical relevance (Fletcher 2007). In any case, "only the most robust statistical distributions permit meaningful linguistic interpretation" (Mair 2007: 444). 
Wierzbicka (in press) explores the use of Google searches to ascertain the relative frequencies of various collocational alternates and collocational preferences, finding, for example, that among expressions of the form a deep sense of $X$, the word shame is much more frequent than responsibility, whereas the reverse applies to expressions of the form $a$ strong sense of $X$. Wierzbicka's favored technique is the use of proportions. Some differences of this kind are so dramatic that it is hard to believe they are not significant.

Following the lead of Mair (2007) and Wierzbicka (in press), I used the Google search engine to explore the distribution of "serious expressions" in "pages from Australia", as opposed to the English-language Web generally. ${ }^{7}$ The searches were repeated at regular intervals over a number of weeks, and the results averaged and rounded. The figures given below are the absolute numbers and percentages of "hits" reported by the first query. This means that they represent the number of webpages reported as matching the queries, not the number of actual occurrences on the pages. ${ }^{8}$ Needless to say, Australian webpages represent only a small fraction of the total Google-indexed English-language web - almost certainly less than $5 \%$. Nevertheless, some of the figures obtained seem to provide striking evidence in favor of the contentions developed earlier in this study. The most dramatic concern the following two strings: "to take anything too seriously" and "not taking yourself too seriously." Such expressions tend to occur in contexts where someone is giving general "life advice" or commentary, or stating a general principle. It therefore seems very telling that the proportion of webpages from Australia containing such expressions is much higher than one would expect from the size of the Australian section of the Web; see Table 3.

It is important to note that similarly skewed results are not found with many other "not-too-seriously expressions". In the third-person, for example, i.e. expressions like "he/she doesn't take him/herself too seriously," the figures for Australia are no higher than those on the Web generally. This reflects the fact that in all Anglo speech cultures, including

Table 3. Webpages from Australia with key "not-too-seriously expressions" as a percentage of webpages on English-language web as a whole, as reported by Google (based on four checks in June 2007, rounded and averaged)

\begin{tabular}{llll}
\hline & $\begin{array}{l}\text { \# pages from } \\
\text { Australia }\end{array}$ & $\begin{array}{l}\text { \# pages } \\
\text { on Web }\end{array}$ & $\begin{array}{l}\text { Australian pages } \\
\text { as \% of Web }\end{array}$ \\
\hline to take anything too seriously: & 180 & 830 & $22 \%$ \\
not taking yourself too seriously: & 160 & 840 & $19 \%$ \\
\hline
\end{tabular}


Table 4. Webpages from Australia and webpages from UK with two "take-the-piss expressions" (based on two checks in June 2007, averaged and rounded)

\begin{tabular}{lcc}
\hline & \# pages from Australia & \# pages from UK \\
\hline taking the piss: & 23,600 & 88,700 \\
take the piss: & 9,700 & 55,000 \\
totals: & 33,300 & 143,700 \\
\hline
\end{tabular}

Anglo-American speech culture, it can be seen as admirable that someone "doesn't take him/herself too seriously" - especially if that person is a celebrity or other famous person, and interviews with such people are well represented on the Web. But there is a difference between a positive trait being seen as potentially admirable, on the one hand, and an active proscription, such as the active proscription against taking yourself seriously in Australia.

As a second example, we can consider the range of use of "TAKE the piss/mickey". What can we say about its distribution in Australia as opposed to the UK? My analysis predicts that there ought to be a significant difference, inasmuch as it claims that in Australia the usage of this expression is driven not only by general "pro-humor" scripts shared with British English, but also by some specifically Australian cultural scripts which mandate active efforts to appear to be "like other people", and which discourage feelings of specialness. What do the Web and the Google search engine have to tell us about this?

First consider the figures presented in Table 4 comparing the number of hits reported on the first query on "Pages from Australia" and "Pages from UK" (accessed via google.co.uk). The absolute figure of UK pages is about four times greater, but this is only to be expected, given the much greater number of UK webpages overall.

If we consider the figures for "TAKE the piss" with a reflexive object, however, the situation is dramatically different. Before inspecting the figures, here are some examples (from Australian webpages) of the kind of contexts in which these expressions occur.

(15) Richie [cricket commentator Richie Benaud] was soon taking the mickey out of himself, though, demonstrating that it is good not to take yourself too seriously.

(16) He was taking the piss out of himself as much as anyone else in the process, but no one seemed to recognize it. In fact, it was his central tenet to writing.

(17) So anyone can be aussie whether they've lived here all their life, just visited, or never been here but still enjoy taking the piss out of 
themselves and everyone else, while being generally laid back people.

Table 5. Webpages from Australia and webpages from UK with "TAKE the piss out of himself/themselves" (based on two checks in June 2007, averaged and rounded)

\begin{tabular}{lll}
\hline & \# pages from Australia & \# pages from UK \\
\hline the piss out of himself & 320 & 120 \\
the piss out of themselves & 390 & 140 \\
\hline
\end{tabular}

Notes: The queried expressions did not actually contain take, in any of its forms, because the string "the piss out of himself/themselves" almost never occurs except with the verb take.

For examples of this kind, i.e., with a reflexive object, the reported number of pages is about four times greater on "Pages from Australia" than on "Pages from UK". If we adopt the multiplier factor of four for the difference in the number of pages overall, it would seem that such expressions are more than ten times more frequent in the Australian domain than in the UK domain.

My tentative conclusion is that the web data on relative frequencies of key expressions in different varieties of English supports the hypotheses developed from semantic and ethnopragmatic analysis. ${ }^{9}$ Based on the web evidence, it would appear that the key "not-too-seriously" expressions are used relatively more frequently in Australian English than in American and British English, as predicted; and it appears that taking the piss/mickey out of yourself is more frequently spoken about in Australia than in the UK, as predicted.

In short, the available evidence from frequency data converges with conclusions from cultural commentary and ethnopragmatic analysis. Not taking yourself too seriously is a strongly mandated cultural priority in Australia, with significant implications for the tone and timbre of ordinary social interaction.

\section{Discussion and concluding remarks}

I would not deny that the present study labors under several difficulties, and not only the practical problems of corpus work. First, the web data is aggregated and does not allow us to separate out and investigate the internal variation that must surely be there. Future studies attempting a more finely differentiated and nuanced description would be most welcome, as would be attempts to study how discourse-related norms and 
values may be changing in today's dynamic and heterogenous Australian society.

I rather doubt, however, that the picture developed in this study represents only "white, middle class, middle-age Australians", as asserted by one reviewer of this paper. Consider the following selection of naturally occurring examples. In (18), the Australian musician MC Suffa from the hip-hop group Hilltop Hoods comments on their album "The Calling". Example (19) comes from the webpage of the Victorian Youth Symphony Orchestra, an amateur symphony orchestra. Example (20) is from Susan Carland, a young Australian Muslim who is one of the originators of the SBS TV comedy program Salam Café. Example (21) is a quote from the Australian indigenous humor researcher Lilian Holt. ${ }^{10}$

(18) We take the piss out of ourselves on this album. It's probably more casual. We're a bit more laid-back about [the recording process] then we used to be. Before, we were a bit too serious. [SMH 7/11/ 03, smh.com/webarchive]

(19) We rehearse once a week and put on concerts of a good standard. But we don't take ourselves too seriously. [home.vicnet.net.au/ $\sim$ vyso/]

(20) People like the fact we are willing to laugh at ourselves and our situations. You either reclaim what can be a really grim situation with humor or you get frustrated, mad and dejected. [Weekend Australian 17-18/05/08]

(21) [Aboriginal humor] is quite laconic and dry ... It's about laughing at ourselves and others and letting it go ... I think that humor is such a bonus, such a gift, to be able to langh at yourself and not to take yourself too seriously. [SMH 02/01/07]

A second difficulty concerns the unit of analysis. Does it really make sense to speak of a "speech community", "discourse community", etc. in relation to Australian English? Is it acceptable to speak of "Australian English" at all, even with qualifications such as "mainstream AngloAustralian English", when such usage carries with it the dangers of being essentialist and exclusionary? Briefly put, my view is that although these terms are approximate and conceptually fuzzy and permit only a high level of generalization, it is better to use them and to attempt to move the research forward than risk the dangers of not addressing issues of language, discourse and culture. There is the danger of closing our eyes to valid generalizations about discourse practices and their cultural underpinnings. There is the danger of refusing to admit what is obvious to every newcomer to Australia, namely, that prevailing ways of speaking and interacting in this country are significantly different from those of 
other countries, including the UK and USA. There is the danger of professional linguists failing in their responsibility to provide some practical advice and guidance that could help ease problems of cultural adaptation and intercultural communication.

The present study has explored the nexus between cultural values and attitudes, discourse practices, and the usage patterns of linguistic expressions. With Wierzbicka (2002), Peeters (2004a, 2004b, 2007), Haugh $(2007,2008)$ and others, I hope to have contributed to potential improvements in intercultural communication and understanding between speakers of Australian English and speakers of other national varieties. More broadly, I hope that the present study demonstrates the potential for ethnopragmatic analysis, based on linguistic evidence, to provide explanatory insider perspectives on speech practices.

\section{Acknowledgements}

The explications and scripts have been have discussed at length with Anna Wierzbicka, and they incorporate numerous suggestions and ideas from her. My research assistant Vicki Knox undertook a great deal of the corpus management and analysis reported in this study, as well as making many helpful suggestions about the semantic analysis. I am grateful to Bert Peeters for helpful critical comments and suggestions about the explications. Some important ideas and examples came from Sophie Nicholls. Participants at the IPrA 2007 workshop on "Corpus Pragmatics" held in Göteborg, Sweden, contributed a number of valuable comments. Finally, two anonymous reviewers for this journal made comments which prompted significant revisions to an earlier version. This work was supported in part by the Australian Research Council.

\section{Notes}

1. Needless to say, public discourse about Australian identity is saturated with political and ideological assumptions and is thus highly contested. My point here is that "not taking yourself too seriously" forms part of the self-stereotype at play in this discourse, along with other expressions such as "the fair go" and "the tall poppy syndrome", etc. which have already come to scholarly attention.

2. Mair (2007) includes TAKE the mickey as an "established collocational marker of Britishness", and though his frequency figures show that Australia is the country in which it is next most common, the Australian figure is much lower than the UK figure. Mair's account is incomplete, however, because he does not take account of its synonymous, but non-euphemistic, counterpart TAKE the piss. Given the general Australian acceptance of "bad language" (Wierzbicka 2002), in Australia TAKE the piss is much more common than its milder counterpart. 
3. As one might expect, polysemy is frequently a complication when trying to identify primes and match them up across languages. Often the range of use of exponents of the same prime do not coincide because aside from the identical shared meaning, the words in question also have additional meanings which differ from language to language; see especially the studies in Goddard and Wierzbicka $(1994,2002)$ and Goddard (2008).

4. Wierzbicka (in press) argues that a sense of humor has no exact equivalent in other European languages, let alone in other languages of the world. She points out that the French expression le sens de l'humour, for example, borrowed into French from English, is not the exact semantic equivalent of its English model. One could not qualify le sens de l'humour as bon "good", though in English the expression a good sense of humor is much more frequent than the unqualified sense of humor alone.

5. Possibly script [E] should be augmented in Australia with another script relating specifically to the value of humor as a reaction to personal misfortune, even to personal tragedy. A well-established line of historical and literary interpretation could be adduced in support of this proposal (cf. Willey 1984; Jones and Andrews 1988; Thornhill 1992; De Groen and Kirkpatrick 2009). In response to the hardships of the convict experience, then the crushing disappointment of chronic drought, barren soils, and the rest, "life is made bearable by being treated as a joke" (Clark 1976: 30). At a first pass, one could suggest the following script: "people think like this: when something very bad happens to me, it is good if I can laugh [M] when I think about it."

6. Ransom (2001) mounts a sharp critique of Wierzbicka's position, which for some reason he terms the "trivialisation of Australian culture". Her response can be found in Wierzbicka (2001).

7. There is no easy way to use the country domains to separate pages from the USA from other pages. I am unconvinced of the validity of Mair's (2007) strategy of using the .edu (academic) domain.

8. Nor are Google's "reported hits" figures completely accurate, because as far as outside observers can tell, Google does not index the entire Web. The figures given for the number of hits are the result of an algorithm which extrapolates from the indexed pages to the web as a whole (Véronis 2005).

9. There are methodological lessons here for the emerging field of contrastive corpus pragmatics. It seems that the relative frequencies of highly specific expressions can be more pertinent to hypothesized cultural differences than raw figures at the "whole lemma" level. For optimal results therefore, semantic analysis and corpus work need to go hand in hand. The identification and selection of key expressions must be guided by semantic analysis.

10. It has been suggested that mainstream Australian humor styles, such as "taking the mickey" and other forms of aggressive joking and mockery, may have been heavily influenced by indigenous Aboriginal humor (Clendinnen 2003; Davis 2007, 2009), blending with the Cockney and Irish humor of early settlers.

\section{References}

Australian Oxford Dictionary. (1999). Bruce Moore (ed.), Melbourne: Oxford University Press.

Brown, Penelope and Stephen C. Levinson (1987[1978]). Universals in language usage: Politeness phenomena. In Questions and politeness: Strategies in social interaction, Ester Goody (ed.), 56-310. Cambridge: Cambridge University Press. [Re-issued as Penelope 
Brown and Stephen C. Levinson. 1987. Politeness. Cambridge: Cambridge University Press. ]

Carr, Bob (2003). What Australia means to me. Camberwell, Vic.: Penguin Books.

Clark, Manning (1976). A discovery of Australia: 1976 Boyer Lectures. Sydney: ABC.

Clendinnen, Inga (2003). Dancing with strangers. Melbourne: Text Publishing Company.

Davis, Jessica Milner (2007). "Taking the mickey": A brave Australian tradition. The Fine Print 4 (August 2007), http://www.emendediting.com/html/ezine/issue4/pdfs.mickey. pdf.

Davis, Jessica Milner (2009). "Aussie" humour and laughter: Joking as an acculturating ritual. In A serious frolic: Essays in Australian humour, Fran De Groen and Peter Kirkpatrick (eds.), 31-47. St Lucia, Qld.: University of Queensland Press.

De Groen, Fran and Peter Kirkpatrick (eds.) (2009). A serious frolic: Essays in Australian humour. St Lucia, Qld.: University of Queensland Press.

Fletcher, William H. (2007). Concordancing the Web: Promises and problems, tools and techniques. In Corpus linguistics and the Web, Marianne Hundt, Nadja Nesselhauf and Carolin Biewer (eds.), Amsterdam: Rodopi. http://kwicfinder.com/FletcherConcordcing Web2005.pdf (accessed 21/05/07).

Fox, Kate (2004). Watching the English. London: Hodder.

Goddard, Cliff (2006a). "Lift your game, Martina!"-Deadpan jocular irony and the ethnopragmatics of Australian English. In Ethnopragmatics: Understanding discourse in cultural context, Cliff Goddard (ed.), 65-97. Berlin: Mouton de Gruyter.

Goddard, Cliff (2007a). Semantic molecules. In Selected papers of the 2006 Annual Meeting of the Australian Linguistic Society. Ilana Mushin and Mary Laughren (eds.), http:// www.als.asn.au.

Goddard, Cliff (2007b). A response to N. J. Enfield's review of Ethnopragmatics. Intercultural Pragmatics 4(4). 531-538.

Goddard, Cliff (ed.) (2006b). Ethnopragmatics: Understanding discourse in cultural context. Berlin: Mouton de Gruyter.

Goddard, Cliff (ed.) (2008). Cross-linguistic semantics. Amsterdam: John Benjamins.

Goddard, Cliff and Anna Wierzbicka (1997). Discourse and culture. In Discourse as social interaction (Discourse studies: A multidisciplinary introduction, Vol 2). Teun A. van Dijk (ed.), 231-257. London: Sage.

Goddard, Cliff and Anna Wierzbicka (eds.) (1994). Semantic and lexical universals-theory and empirical findings. Amsterdam: John Benjamins.

Goddard, Cliff and Anna Wierzbicka (eds.) (2002). Meaning and universal grammar-theory and empirical findings. Vols I and II. Amsterdam: John Benjamins.

Goddard, Cliff and Anna Wierzbicka (eds.) (2004). Cultural scripts. Special Issue of Intercultural Pragmatics 1(2).

Haugh, Michael (2007). "Can you pass us the salt?" The interactional achievement of connectedness and politeness in Australian English. Paper presented at the Third International Symposium on Politeness, University of Leeds, July 2-4 2007.

Haugh, Michael (2008). "Taking the piss": Jocular mockery and face in Australian English. Australian Linguistics Society Annual Conference, University of Sydney, July 2-4 2008.

Hirst, John (1998). Egalitarianism. In The Oxford companion to Australian history, Graeme Davidson, John Hirst, and Stuart Macintyre (eds.), 208-209. Melbourne: Oxford University Press.

Hirst, John (2006). The distinctiveness of Australian democracy. In Sense and nonsense in Australian history, 292-312. Melbourne: Black Inc. Agenda.

Hofstede, Geert (1997). Cultures and organisations: Software of the mind. New York: McGraw Hill. 


\section{Cliff Goddard}

Horne, Donald (1986[1964]). The lucky country. 3rd edn. Melbourne: Penguin Books.

Jackendoff, Ray (2007). Conceptual semantics and natural semantic metalanguage theory have different goals. Intercultural Pragmatics 4(3). 411-418.

Jones, Dorothy, and Barry Andrews (1988). Australian humour. In The Penguin new literary history of Australia, Laurie Hergenhan (ed.), 60-76. Ringwood, Vic.: Penguin.

Kissane, Karen (2002). Accidental heroes. The Age 25/10/02. http://www.theage.com.au/ articles/2002/10/25/1035504884295.html.

Mair, Christian (2007). Varieties of English around the world: Collocational and cultural profiles. In Phraseology and culture in English, Paul Skandera (ed.), 437-468. Berlin: Mouton de Gruyter.

Malouf, David (2004). Made in England: Australia's British inheritance. Quarterly Essay 12.

Murray, Les (1999). Some religious stuff I know about Australia. In The quality of sprawl. Thoughts about Australia, 19-50. Sydney: Duffy and Snellgrove.

Olivieri, Kate Margaret (2003). A semantic analysis of teasing-related speech act verbs in Australian English. Armidale: University of New England BA Hons thesis.

Ramsom, William S. (2001). Anna Wierzbicka and the trivialization of Australian culture. Australian Journal of Linguistics 21(2). 181-194.

Peeters, Bert (2000). "S'Engager" vs. "To show restraint": Linguistic and cultural relativity in discourse management. In Evidence for linguistic relativity, Susanne Neimeier, and René Dirven (eds.), 193-222. Amsterdam: John Benjamins.

Peeters, Bert (2004a). Thou shalt not be a tall poppy: Describing an Australian communicative (and behavorial) norm. Intercultural Pragmatics 1(1). 71-92.

Peeters, Bert (2004b). Tall poppies and egalitarianism in Australian discourse: From key word to cultural value. English World-Wide 25(1). 1-25.

Peeters, Bert (2007). Australian perceptions of the weekend: Evidence from collocations and elsewhere. In Phraseology and culture in English, Paul Skandera (ed.), 79-108. Berlin: Mouton de Gruyter.

Peeters, Bert (ed.) (2006). Semantic primes and Universal Grammar: Evidence from the Romance languages. Amsterdam: John Benjamins.

Schmied, Josef (2006). New ways of analysing ESL on the WWW with WebCorp and WebCountPhrase. In The changing face of corpus linguistics, Antoinette Renouf, and Andrew Kehoe (eds.), 309-324. Amsterdam: Rodopi.

Sharp, Isla (2001). Culture shock! Australia. Portland, OR: Graphic Arts Center Publishing.

Singelis, Theodore M., Harry C. Triandis, Dharm P. S. Bhawuk, and Michele J. Gelfand (1995). Horizontal and vertical dimensions of individualism and collectivism: A theoretical and measurement refinement. Cross-Cultural Research 29(3). 240-275.

Stubbs, Michael (2001). Words and phrases: Corpus studies of lexical semantics. Massachusetts: Blackwell Publishers.

Thornhill, John (1992). Making Australia. Sydney: Millennium Books.

Véronis, Jean (2005). Web: Google's missing pages: Mystery solved? Technologies du Langage. http://aixtal.blogspot.com/2005/02/web-googles-missing-pages-mystery.html.

Wierzbicka, Anna (1972). Semantic primitives. Frankfurt: Athenaum.

Wierzbicka, Anna (1992). Semantics, culture, and cognition: Universal human concepts in culture-specific configurations. Oxford: Oxford University Press.

Wierzbicka, Anna (1994). "Cultural scripts": A new approach to the study of cross-cultural communication. In Language contact, language conflict, Martin Pütz (ed.), 69-87. Amsterdam: John Benjamins.

Wierzbicka, Anna (1996). Semantics: Primes and universals. Oxford: Oxford University Press. 
Wierzbicka, Anna (2001). Australian culture and Australian English: A response to William Ramson. Australian Journal of Linguistics 21(2). 195-214.

Wierzbicka, Anna (2002). Australian cultural scripts-bloody revisited. Journal of Pragmatics 34(9). 1167-1209.

Wierzbicka, Anna (2003). Cross-cultural pragmatics [expanded 2nd edn]. Berlin: Mouton de Gruyter.

Wierzbicka, Anna. (2006a). English: Meaning and culture. New York: Oxford University Press.

Wierzbicka, Anna (2006b). Anglo scripts against "putting pressure" on other people and their linguistic manifestations. In Cliff Goddard (ed.), Ethnopragmatics: Understanding discourse in cultural context, 31-63. Berlin: Mouton de Gruyter.

Wierzbicka, Anna (2007a). Theory and empirical findings: A response to Jackendoff. Intercultural Pragmatics 4(3). 399-409.

Wierzbicka, Anna (2007b). NSM Semantics versus Conceptual Semantics: Goals and standards (a response to Jackendoff). Intercultural Pragmatics 4(4). 521-529.

Wierzbicka, Anna (2007c). Reasonably well: Natural Semantic Metalanguage as a tool for the study of phraseology and its cultural underpinnings. In Phraseology and culture in English, Paul Skandera (ed.), 49-78. Berlin: Mouton de Gruyter.

Wierzbicka, Anna. In press. Evidence, experience, sense: The hidden cultural legacy of English. New York: Oxford University Press.

Willey, Keith (1984). You might as well laugh, mate: Australian humour in hard times. South Melbourne: Macmillan. 